\author{
Gioia-Ana Ulrich Knežević \\ Universiteit van Zagreb \\ https://doi.org/10.18485/bgd_nlistiek_30.2018.ch7
}

\title{
DE BLOEI VAN ‘ONZEDELIJKE’ KROATISCHE LITERATUUR
}

\begin{abstract}
This paper is about booming gay literature in Croatia, a country that is gradually opening to tolerance, although still relatively patriarchal and under a considerable influence of the Catholic paradigm. I will discuss three recent groundbreaking Croatian novels starting with the first gay novel in Croatian history, The Berlin towel, which has paved the way for books covering themes that were, until recently, considered unthinkable. I will compare them to two Dutch novels that were published in the early and mid-twentieth century, starting from the fact that the Netherlands is the leading country in the world when it comes to tolerance, liberalism, freedom and equalization of gay rights. All discussed novels caused commotion and public condemnation, but they have opened the way to tolerance and freedom within conservative societies.
\end{abstract}

Keywords: tolerance, homosexuality, liberalism, gay, novel, taboo, groundbreaking, literature

\section{Inleiding}

Nederland is bekend als een homo-tolerant land dat niet alleen in Kroatië gezien wordt als voorbeeldland van de homo-emancipatie. Tolerantie, vrijheid en liberalisme zijn begrippen die buitenlanders met Nederland verbinden. Kroatië is een nogal homofoob land, maar met een groot vermogen voor positieve veranderingen. Die veranderingen zijn ook terug te zien in de Kroatische literatuur. Dit onderzoek behandelt drie baanbrekende romans uit het laatste decennium die voor opschudding zorgden. De recente Kroatische literatuur is een soort pleidooi voor vrijheid en tolerantie, en dit meer dan een eeuw na het verschijnen van De Haans roman Pijpelijntjes, die wel beschouwd wordt als de eerste homo-roman in de Nederlandse letteren. De Nederlandse beschavingsvoorsprong op Kroatië en de voor het lezerspubliek choquerende bloei van de Kroatische homoliteratuur heeft mijn aandacht getrokken als literair vertaalster en docente Nederlandse letterkunde. De eerste Kroatische homo-roman, De Berlijnse handdoek', heeft de weg gebaand voor boeken die tot voor kort 'onvoorstelbare' thema's behandelen. Daarmee is de situatie in de Kroatische literatuur zo radicaal veranderd dat zelfs heteroseksuele schrijvers met homoseksualiteit omgaan in hun proza. Er is

1 Alle citaten uit niet-Nederlandse bronnen zijn in vertaling van de auteur van dit artikel. 
niet alleen sprake van een bevrijding van de Kroatische literatuur, hier gaat het meer om het aannemen van een nieuw onderwerp: de homoseksualistiek (Ožegović 2010:1)

\section{Tolerantie ten opzichte van seksuele geaardheid in Kroatië}

De acceptatie van homoseksualiteit is in het westen van Kroatie en in de hoofdstad Zagreb in de afgelopen tien jaar in kleine mate toegenomen. De eerste Zagreb Gay Pride Parade werd gehouden in juni 2002 op instigatie van de lesbische activisten gemeenschap als gevolg van de traumatische ervaringen van een aantal Kroatische vrouwen die een jaar eerder deelnamen aan het LGBT Pride in Belgrado, Servië. Hoewel de Zagreb Gay Pride al zestien jaar plaatsvindt is de homofobie in Kroatië nog steeds op een vrij hoog niveau. De eerste Gay Pride in de stad Split werd verstoord door duizenden tegendemonstranten, ongeveer tweehonderd deelnemers van de optocht werden bekogeld met stenen, flessen en vuurwerk, er zijn tientallen aanhoudingen verricht en diverse mensen raakten gewond.

Vijftig procent mensen van een andere genderidentiteit of seksuele geaardheid ervaren in Kroatië een bepaalde vorm van geweld of mishandeling. Tweederde van deze zaken heeft betrekking op de economische, psychologische intimidatie en discriminatie, en er zijn tal van gevallen van fysiek geweld. De situatie gaat heel langzaam vooruit, vooral door het feit dat het aantal deelnemers aan de Gay Pride Parades van jaar tot jaar groeit. De taboes werden doorbroken en LGBT mensen zijn meer open, zij spreken met minder angst over hun seksuele geaardheid en genderidentiteit. Toch is het aantal mensen voor wie homoseksualiteit onnatuurlijk is niet significant verminderd, zoals blijkt uit het onderzoek van niet-gouvernementele organisaties. Ongeveer zestig procent van de Kroatische burgers verzetten zich tegen de samenkomst van LGBT personen. Sinds 2014 bestaat er in Kroatië het geregistreerd partnerschap, dat vrijwel gelijk is aan een huwelijk maar zonder kinderadoptie. Deze wet zorgde voor grote opschudding en er ontstond zelfs een beweging tegen het geregistreerd partnerschap, het initiatief Namens de familie. Zijn doel was niet alleen de 'bescherming' van het huwelijk maar ook de permanente ontzegging van veel meer rechten voor de homoseksuele vrouwen en mannen.

\section{Tolerantie ten opzichte van seksuele geaardheid in Nederland}

In vergelijkend onderzoek tussen verschillende landen zijn de Nederlanders degenen met de minst negatieve houding ten opzichte van homoseksualiteit. Uit een onderzoek uit 2003 blijkt dat slechts tien procent van de Nederlandse bevolking een negatieve attitude heeft ten aanzien van LGBT personen (Kuyper \& Bakker 2006: 18). In de Kroatische pers komt men vaak dergelijke opschriften tegen: Nederland is een land met de hoogste normen van de gewaarborgde rechten en vrijheden van de mens; het meest liberale land ter wereld; Nederland is het vlaggenschip van de wereld in de gelijkschakeling van de burgerlijke rechten van homoseksuele en heteroseksuele 
gemeenschappen; in het algemeen is Nederland de anderen tenminste een stap voor in de legalisering van omstreden politieke beslissingen, zoals het homohuwelijk en softdrugs, evenals hardere taboes van de 21e eeuw - prostitutie en euthanasie.

Een hoge welvaart in een land levert tolerantere mensen, daar zij met andere normen en waarden omgaan. In Nederland wordt in het onderwijs ook vaak aandacht besteed aan homoseksualiteit. Dit is niet het geval in katholiek Kroatië. Ondanks de Nederlandse welvaart, is het helder dat nog lang niet iedereen homoseksualiteit tolereert. Dit kan door het geloof komen, maar ook door eigen normen en waarden. $\mathrm{Al}$ een lange tijd is de tolerantie van homoseksualiteit in Nederland geen groot probleem meer, tenminste als men naar de cijfers kijkt. De jonge generaties groeien op in een maatschappij waar homoseksualiteit zo goed als geaccepteerd is (Bosman \& Duivenvoorden2013: 15).

Volgens de Nederlandse publicatie Gewoon doen. Acceptatie van homoseksualiteit in Nederland uit 2006 (Keuzenkamp et al.) bestaan er ook in Nederland grenzen aan de acceptatie van homoseksualiteit. Homoseksuele vrouwen en mannen moeten niet publiekelijk uiting geven aan hun seksuele voorkeur. De ogenschijnlijke alsmaar positievere attitude van de Nederlanders zou volgens de bovengenoemde publicatie in contrast staan met homo negatieve ervaringen van homoseksuele mannen en lesbische vrouwen. Het zou dan echter gaan om dikwijls onbedoelde, moeilijk te observeren uitspraken ten opzichte van homoseksualiteit die als negatief op te vatten zijn. Een voorbeeld dat wordt genoemd is de uitspraak: 'homoseksuelen overdrijven het belang van hun seksuele voorkeur' (Kuyper \& Bakker 2006: 9).

\section{Taboebrekers - van Kroatië in 2006 naar Nederland in 1904}

Een recente roman die in 2006 in Kroatië voor opschudding zorgde nog voordat hij gepubliceerd werd is De Berlijnse handdoek, geschreven door Dražen Ilinčić, een toen vierenveertigjarige journalist en schrijver uit Zagreb. Zijn boek is een soort mijlpaal in de Kroatische literatuur. Het verhaal van de Berlijnse handdoek begint met de beschrijving van expliciete seks tussen twee mannen. Een van die twee mannen is de veertigjarige verteller die zijn leven als homoseksueel in een soort bekentenis proza beschrijft, door middel van fragmenten uit zijn rijk liefdesleven. Toevallige ontmoetingen, kennismakingen of avonturen via verschillende homoportalen, plezier, passie en de frequente bezoeken aan de lokale homosauna's vormen de kern van dit proza. Maar seks, hoewel begrepen als het gay-imperium, is slechts één aspect van de onderwerpen die Ilinčić in zijn roman aanpakt. Liefde en schoonheid zijn twee andere gelijkwaardige thema's. Verlangen naar een vaste partner en een volmaakte liefde zijn opgevat als een zelden bereikt ideaal en een reden voor het lijden, en terwijl de schokkende scènes de Kroatische kleinburgerij en de puristen in verbazing hebben gebracht, wordt eigenlijk een melancholische en trieste bekentenis van het eeuwige menselijke verlangen naar liefde geschetst, al was het maar voor twee uur, ongeacht de seksuele voorkeuren. Schoonheid is een aspect van deze roman aan wie de auteur in het laatste deel de aandacht geeft. Hij geeft de schoonheid een belangrijke rol bij het 
kiezen van partners en het verwezenlijken van zijn seksueel verlangen, en dat doet hij vaak met humor:

Het is een schitterend leven, het leven van mooie mensen; ik moet nog slechts erachter komen hoe ik mijn hoofd thuis kan laten, in een donkere kast dus, om onbelemmerd te kunnen leven volgens de beroemde Engelse uitdrukking: to come out of the closet - letterlijk 'uit de kast komen', toegeven dat je homoseksueel bent, zich outen - ik moest niet geheel naar buiten komen; mijn hoofd had ik beter in die kast gelaten (Ilinčić 2006: 103).

Ergens op de achtergrond en nooit te uitdrukkelijk zien wij de individuele problemen van de homo-populatie die voortkomen uit het conservatisme en onbegrip van de maatschappij. De roman leest als een soort gids die ons laat zien hoe de Kroatische gay scene functioneert. Het is een intrigerende roman met autobiografische elementen, maar geen pornografische roman, zoals hij meestal werd genoemd, want tussen de expliciete seksuele episodes wordt een reeks van gruwelen beschreven die de homoseksuelen overkomen. De roman mist een stevigere structuur, men zou eigenlijk eerder over fragmenten van bekentenis proza kunnen spreken. In een interview verklaarde de schrijver dat hij niet gevreesd heeft het boek te publiceren, aangezien boeken in Kroatië weinig invloed hebben. Volgens hem had hij meer angst moeten hebben toen hij in 2004 in een televisieprogramma voor zijn geaardheid uitkwam. $\mathrm{Hij}$ is de eerste publieke persoon in Kroatië die openlijk uit de kast is gekomen. En de enige tot op heden. Ten gevolge van kleinburgerlijkheid werd De Berlijnse handdoek onder de homoseksuele populatie zelf vaak als pornoboek gezien.

En nu een terugblik op Nederland in 1904. Pijpelijntjes is een van de eerste boeken uit de Nederlandse literatuur waarin een homoseksuele relatie openlijk wordt beschreven, een verhouding van twee jonge mannen wier liefde onverbloemd beschreven werd. Daarom wordt het vaak als een emancipatorisch boek gezien:

In zijn armen lag ik - licht-bevend, heel dicht tegen hem aan en een rose tinteling liep onder m'n warme huid door.... 'Sam, we doen toch eigenlijk niets ergs... ik hou alleen maar van je.' 'Jazeker, het is niets hoor... je bent een beste boy'... 'Sam, ben-je heusch zoo leelijk als de lui zeggen?' 'O, jé, nog veel leelijker..... 'En ik hou zoo van je, ik hou vreeselijk van je' (De Haan 1974: 23).

Kort na het verschijnen ontstond om deze roman een rel, veroorzaakt door de inhoud van het boek (Simons 1974: 221). Het publiceren van Pijpelijntjes had ook grote gevolgen voor Jacob Israel de Haan. Hij werd ontslagen op de school waar hij lesgaf en bij de krant waarvoor hij schreef. De roman was opgedragen aan zijn vriend Arnold Aletrino die geschrokken raakte toen hij de roman las. Hij herkende zichzelf in een van de personages en verbrandde alle exemplaren die hij kon kopen. De homoseksuele lezers van Pijpelijntjes vonden zelf dat er in het boek veel te negatief over hen werd geschreven. 
Hoewel De Berlijnse handdoek verontwaardiging heeft uitgelokt vanwege de expliciete beschrijvingen van homoseksuele relaties, heeft hij de weg gebaand voor een nieuwe generatie van jonge schrijvers en activisten. In 2008 werd de tweede homoroman gepubliceerd, Op mijn Ikeabank, geschreven door Luka Marić (1974). Zijn boek heeft nog voor de officiële promotie veel succes ervaren en was in de top tien van de bestverkochte boeken. De roman is de getuigenis van de tragedie van de homoseksuele bevolking die verborgen in een hoek zit en gedwongen is te zwijgen:

Ja, kijk, ik wou niet zwijgen. [...] Ik word ziek van het zwijgen! Kom... ga zitten, steek een sigaret op. Je kunt op mijn Ikea bank gaan zitten. Maar dit is niet het punt; als alle stotteren, gaat het nog een groter probleem worden. Verdomme, ik wil zeggen dat ik genoeg van dergelijke verhalen op andere banken heb gehoord. Ze huilde, ze die een man heeft, hij die haar man heeft gehad huilde ook. En de man moest daarvan walgen. [...] Vervolgens deelden zich de Kroaten, de Serviërs, de Slovenen, de Bosniërs... Op die en die. Degenen op straat en degenen in de familie deden alsof ze niets wisten. Alsof zulke dingen niet bestaan en alsof we verdomme twee verschillende werelden zijn. Hou je hoofd omhoog. Kijk naar de hemel. Hij is hetzelfde als de mijne. En onder hem jij en ik en degenen zoals jij en degenen die op mij lijken. Begrijp je nu dat de bank onbelangrijk is? Dat ik niet kon zwijgen. En niets mooier kon maken (Marić 2008: 4).

Marić vertelt onverbloemd en zonder de feiten te verbergen over iets wat voornamelijk door heteroseksuele mannen veracht word - het feminiseren. Voor hem is het een deel van zijn identiteit waarmee hij moet omgaan evenals met zijn homo-bestaan in een kleine stad aan de Kroatische kust waar hij als ober werkt. De vaak niet in verbinding staande en gefragmenteerde passages geschreven in alledaagse omgangstaal onthullen ongelukkige liefdes, minnaars, expliciete seksscènes die zich met verlangens, dromen en frustraties mengen. In de queer context is het boek meer dan welkom, hij heeft zelfs een bepaalde historische waarde, maar is van geen bijzondere literaire kwaliteit. De auteur zelfs noemt zijn roman een schrijfpoging.

\section{Ik ben vrouw en ik hou van vrouwen}

De eerste roman in Kroatië met een lesbische thematiek is Leen me een glimlach, geschreven door Nora Verde (1974) en gepubliceerd in 2010. Nora Verde is het pseudoniem van Antonela Marušić, een jonge journaliste uit Split. De schrijfster legde uit dat zij het boek onder een schuilnaam heeft gepubliceerd met de bedoeling dat de lezers de aandacht vestigen op de kwaliteit en niet op de auteur die voor een groot deel autobiografisch schrijft en zelf ook lesbisch is. Het boek is een soort felle bekentenis proza, gestructureerd als dagboek:"Ik rook wiet. Ik hou van vrouwen. [...] Ik eet geen wit brood. Ik ga niet naar de kerk op zon- en feestdagen” (Verde 2010: 78).

De schrijfster geeft een overzicht van haar verleden en haar heden en herinnert 
zich haar 'gevaarlijke' jaren (feestjes, hedonisme), het opgroeien, haar studiejaren en het proces van haar outing. De verteller behoort tot de generatie van buitenstaanders die opgegroeid zijn in een sfeer van oorlog, die niet een deel van de massa wilden uitmaken en voor een hardere weg hebben gekozen. Het boek werd vooral door de zogenaamde subculturele groepen geaccepteerd als een soort welkome verfrissing, terwijl het voor de conservatieve anderen schokkend proza is waarop heftig gereageerd werd. En dit in 2010! In 1948 werd er in Nederland geschokt gereageerd op Anna Blamans roman Eenzaam avontuur.

De homo-erotische passages in Blamans roman zorgden voor verwarring in de confessionele pers, tot groot ongenoegen van conservatief en christelijk Nederland. In 1949 wordt er zelfs een schijnproces tegen Blaman gevoerd. In het boek spelen stormachtige gevoelens een rol en breekt Blaman een paar taboes door. De lesbische gevoelens van een van de vrouwelijke figuren, 'masculien' genoemd in het boek, konden sommigen niet verdragen. Toch gebeurt er niets schokkends in het boek en seks wordt niet direct beschreven (Zuiderent 1998:25). Blaman zette zich in voor lesbische vrouwen, zij was toen al een en gevierd en gewaardeerd schrijfster en ook Simon Vestdijk loofde haar werk.

\section{Besluit}

Uit voorgaand onderzoek blijkt dat alle besproken romans taboes raken. Zij hebben publieke veroordeling veroorzaakt hoewel $\mathrm{zij}$ in verschillende tijden verschenen zijn. Het publiceren van de Kroatische romans heeft ruimtes van vrijheid binnen de traditionele samenleving geopend, onder het leidende wereldbeeld en de invloeden van het katholieke paradigma. De groei van de beschaving evenals de economische groei in het kader van de Europese manier van denken opent de weg naar de ruimte van tolerantie, zelfs in de nog deels patriarchale Kroatische samenleving.

\section{Literatuuropgave}

Blaman, A. 2012 . Eenzaam avontuur. Amsterdam: J.M. Meulenhoff

Haan, de J. I. 1974. Pijpelijntjes. Den Haag: Kruseman's Uitgeversmaatschappij

Ilinčić, D. 2006. Berlinski ručnik. Zagreb: Fokus komunikacije

Keuzenkamp, S., D. Bos, J.W. Duyvendak \& Hekma, G. 2006. Gewoon doen. Acceptatie van homoseksualiteit in Nederland. Den Haag: Sociaal en Cultureel Planbureau

Kuyper, L. \& Bakker, F. 2006. De houding ten opzichte van homoseksualiteit. Een beschrijvende literatuurstudie. Den Haag: Sociaal en Cultureel Planbureau

Marić, L. 2008. Na mom Ikea kauču. Zagreb: Celeber 
Ožegović, N. 2010. “Gay literatura šokira Hrvatsku.” In: Nacional, nr. 738 (04. januari 2010) pp. 14-15

Simons, W. J. 1974. 'Pijpelijntjes. De geschiedenis van een 'onzedelijk' boek'. In: Haan, de J. I.,Pijpelijntjes. Den Haag: Kruseman's Uitgeversmaatschappij, pp. 219-243

Verde, N. 2010. Posudi mi smajl. Zagreb: Meandarmedia

Zuiderent, E. 1998. 'Anna Blaman en de moraal van het lezersdom'. In: Passionate. Jaargang 5, pp. 24-29

\section{Internetbronnen}

www 1

Bosman, N. \& Duivenvoorden, E. 2013. Tolerantie van homoseksualiteit. Laatst geraadpleegd op: 17 oktober 2017 van yeswiki.nl/images/2/25/Tolerantie_ homoseksualiteit.pdf

www 2

Cuculić, K. 2011. U Rijeci predstavljen roman "Posudi mi smajl”. Laatst geraadpleegd op: 22 september 2017 vanhttp://www.novilist.hr/index.php/Kultura/Knjizevnost/URijeci-predstavljen-roman-Posudi-mi-smajl?meta_refresh=true

www 3

Pogačnik, J. 2006. Dražen Ilinčić - Berlinski ručnik. Laatst geraadpleegd op: 14 mei 2017 van http://www.mvinfo.hr/clanak/drazen-ilincic-berlinski-rucnik

www 4

Pogačnik, J. 2008. Luka Marić: Na mom Ikea kauču. Laatst geraadpleegd op: 16 mei 2017 van http://www.mvinfo.hr/clanak/luka-maric-na-mom-ikea-kaucu

www 5

Srdoč, S. 2013. Nizozemska - carstvo čula i visokih kriterija. Laatst geraadpleegd op: 20 juli 2017 van http://www.tportal.hr/vijesti/svijet/270870/Nizozemska-carstvocula-i-visokih-kriterija.html 